\title{
Can parts cause their wholes?
}

\author{
Toby Friend ${ }^{1}(\mathbb{D}$
}

Received: 31 May 2017 / Accepted: 12 January 2018 / Published online: 25 January 2018

(C) The Author(s) 2018. This article is an open access publication

\begin{abstract}
Part-whole causation (PWC) is the thesis that some causes are part of their effects. PWC has been objected to because of its incompatibility with the criterion that causes not be spatially included within their effects and the criterion that causes and effects are ontologically distinct in some sense. This paper serves to undermine the sufficiency of these ways of objecting to PWC by showing that for each criterion either cause-effect relationships need not satisfy it or part-whole relationships can. A case-study of the collapse of Bridge 9340 is employed to facilitate the discussion.
\end{abstract}

Keywords Causation $\cdot$ Parthood $\cdot$ Distinctness

\section{Introduction}

In the philosophy of causation it is common to reject the following thesis: ${ }^{1}$

PWC: Some causes are part of their effects.

Rejection of PWC amounts to a constraint on acknowledged causal relationships and has been applied, for instance, in consideration of counterfactual dependency theories of causation (Lewis 1973, 2000), in debates on the plausibility of mental causation (Kim 2000; Baumgartner 2013; Woodward 2014), in explanation of the role of dispositions in compound law-governed systems (Hüttemann 2009), and in the mechanists'

\footnotetext{
${ }^{1}$ I would very much like to thank Phyllis Illari, Luke Fenton-Glynn and two anonymous referees for their help in my development of this paper.

$凶$ Toby Friend

tobythomasfriend@gmail.com

1 Science and Technology Studies, University College London, Gower Street, London WC1E 6BT, UK
} 
literature where a division between causal and constitutive relationships could be interpreted as being motivated by a denial of part-whole causation (see,e.g., Craver and Bechtel 2007; Craver 2007; Kaiser and Krickel 2017).

In what follows I aim to oppose this trend by building support for PWC. ${ }^{2} \mathrm{My}$ approach divides in two parts. The first is to offer, in Sect. 2, a particular example which satisfies a number of platitudes both about causation and about part-whole relationships. (I confess it is a pity I only have space to provide one case-I think they are abundant!) The example is intended to represent the kind of phenomena I imagine we should be happy to accept as an instance of part-whole causation if we were not otherwise committed to a rejection of PWC. Crucially, I do not present the example as one which cannot be conceivably interpreted in some way other than as a case of part-whole causation. As two anonymous referees were at pains to point out, there are interpretations of the example which pay some respect to the causal intuitions I draw attention to without committing to the thesis. Rather, the example is there to place a burden of proof on PWC's detractors-we could go through careful reinterpretive procedures, but why should we?

This leads to the second part of my support for PWC, which, in Sect. 3, directly confronts the philosophical arguments which have been presented in favour of its rejection. I focus first on the objection that causes cannot be spatiotemporally included within their effects and second on the objection that causes and effects are ontologically distinct in various ways which part-whole relations are not.

Arguing in this way does not permit complete neutrality regarding debates over the nature of causation and parthood and I will attempt to make it clear where those commitments emerge. However, by beginning with the particularist approach and subsequently testing this case against the justification of philosophical positions which would oppose it, I take my methodology to be commendably unmotivated by questionable philosophical prejudice. ${ }^{3}$

Having said that, for clarity's sake I will focus discussion by making a simplifying, but not uncontroversial, assumption. I will assume the kinds of causal and parthood relations we are interested in are between events. As I understand them, events are dated-located entities and therefore have a time and place of occurrence. Examples are the Battle of Trafalgar, my first birthday party, supernova 1987A and the most recent decay of your nearest plutonium atom. ${ }^{4}$ While this assumption is not entirely

\footnotetext{
2 Another question entirely is whether part-whole pairs might also be related as effect to cause; this question concerns the truth of the thesis of whole-part causation: that some effects are part of their causes. While I take it that much of what follows can be transferred over to a discussion of the plausibility of this other thesis, it is important to distinguish the two, since one may prove harder to defend than the other. (See Woodward 2014; Harinen 2014 for some problems which seem to affect only whole-part causation).

3 Admittedly, an eliminativist about causation (e.g. Russell 1912) or part-whole relations (e.g. Cowling 2014) might have trivial reasons to reject PWC. Whilst starting from a relatively theory-neutral position, I don't think its possible to do so consistently with theories which deny the existence of the relevant relations altogether.

4 These dated-located entities have a spatiotemporal location (they are dated and spatially located). But that is not to say they are individuated by their spacetime location (see Davidson 1976; Lemmon 1967; Quine 1985; Davidson 1985 for a discussion of this point ). I am happy to assume for the sake of argument that if one event is part of a second then its spatiotemporal boundaries fall within that of the second, but not that every event whose boundaries fall within that of a second is necessarily a part of the second.
} 
innocent, I take it to be reasonably innocuous for the current discussion. ${ }^{5}$ First, those I will be mentioning who have contributed to the literature dismissing PWC all appear to accept that causation is, and parthood can be, a relation between events. Perhaps there are further complications concerning the plausibility of PWC when it is applied to relata other than events, but at least detractors of the thesis understood as restricted to relata between events are not straw men. Second, it's not obvious to me that the further complications involved in extending the discussion to one concerning facts or states of affairs (the other prominent relata mooted for causal relations) would present a significant barrier to the kinds of arguments presented below, although I will refrain from attempting to show this explicitly.

\section{Collapse of Bridge 9340}

On the 1st August 2007, the Interstate 35W's Bridge 9340, spanning the Mississippi River, collapsed killing 13 and injuring 145. The apparent spontaneity of the collapse, combined with its tragic consequences, lead to a wide-reaching enquiry as to what caused it.

After over a year of enquiry, on the 12th December 2008 the then Chairman of the National Transport Safety Board Mark Rosenker spoke to the Transportation Committee at the National Conference of State Legislatures. He said that,

the I-35W bridge collapsed due to inadequately designed gusset plates [...] The gusset plates were too thin to provide the margin of safety expected in a properly designed bridge such as this. If the gusset plates had been designed correctly, the bridge would not have collapsed under the loads on August 1.

Gusset plates are steel sheets which connect trusses of the bridge together. In agreement with much of the analysis carried out on the bridge after it collapsed, Mark Rosenker's conclusion was that the collapse originated at a particular pair of gusset plates at position 'U10'. This was corroborated by the final report on the adequacy of the gusset plates in Bridge 9340 made by Holt and Hartman of the Federal Highway Administration Turner-Fairbank Highway Research Center.

Reviewing the entire set of D/C [demand-capacity] ratios in total reveals a consistent mis-handling of shear by the designer. The gusset plates at U10 were the most under-designed as a result of this error. When the resulting lack of capacity of these gusset plates was coupled with a violation of the detailing requirements for the unsupported edge, they became the most vulnerable plates in the truss to the affects of any applied loads. In summary, the capacity inadequacies for the U10 gussets were considerable for all conditions investigated with the plate providing approximately one-half of the resistance required by the design loadings without consideration for instability. (2008, p. 16)

Assuming the analysis was accurate, what can we say about the parthood and causal relations in the situation? Brief reflection can make it seem almost undeniable that the

\footnotetext{
5 Thanks to an anonymous referee for suggesting that I make the following responses.
} 
event of the deformation of the U10 gusset plates (nominalised 'U10-failure') was part of the collapse of Bridge 9340 (nominalised 'bridge-collapse'). First recognise that the gusset plates themselves were part of the bridge (they were a feature of the designs for the bridge, inside the bridge's spatial boundaries, etc.). Second, notice that the gusset plates were one of the central components which was severely deformed during the event of the collapse (as soon as they were deforming, the bridge was collapsing and vice versa). Given that there does not appear to be any reason to think that U10-failure and bridge-collapse are merely coincidental, these points in combination should lead us to think that one could not describe bridge-collapse in as full detail as possible without reference to U10-failure. By these observations we have strong reason to believe that U10-failure was part of bridge-collapse.

But is the U10-failure a cause of the bridge-collapse? Again, I think the answer is plausibly 'yes'. In order to support this conclusion, I will consider three platitudes of causation satisfaction of which I take to be strong intuitive support of the existence of a causal relation.

Explanation: It seems clear that U10-failure was an explanation for why the bridge collapsed. A now-popular understanding of explanations is that they inform questions of dependency expressed in 'what would happen if things had been different?' questions (see, e.g., Woodward 2003, Ch.5). ${ }^{6}$ According to this understanding, it is plausible that U10-failure explains bridge-collapse from the chairman of the NTSB's comment that 'if the gusset plates had been designed correctly, the bridge would not have collapsed under the loads.'

Admittedly, it is ambiguous from the chairman's utterance whether he meant to draw attention to the event of the gusset plates being incorrectly designed rather than to the fact of their incorrect design or to the gusset plates themselves. Perhaps all these entities could be attributed a related explanatory role. But no harm appears to be done if we follow the simplifying assumption made in Sect. 1 and focus on relations between events. After all, there do appear to be such events, and it is the occurrence and nonoccurrence of events which are typically related by counterfactual depenence in the sorts of explanation being considered (Lewis 1973, 1986a; Woodward 2003). Under such a reading, the chairman is drawing a connection of dependence between the event of the bridge collapsing and the event of the gusset plates being incorrectly designed. But in this context, it is hard to see how this could amount to an explanation of the event of the collapse unless there were a mediating event concerning the behaviour of the gusset-plates which was both depended on for the event of the collapse and also dependent on the incorrect designing of the plates. U10-failure plays exactly that mediating role.

The dependency of bridge-collapse on U10-failure is further corroborated, if indirectly, by analysts' observation that Bridge 9340 was 'fracture critical' (Holth 2011; Ballarini and Okazaki 2010) 'meaning that if one part of the bridge fails the entire bridge might collapse.' We can infer, therefore, that if the gusset plates had been designed properly, they would not have failed and bridge-collapse would not have

$\overline{6}$ The interpretation employs counterfactual reasoning popularised by Lewis (1973). 
occurred. U10-failure is therefore part of an explanation of bridge-collapse by virtue of informing 'what would happen if things had been different?' questions.

According to many, describing causes is one sure way to explain something (see, esp. Salmon 1998). Moreover, the counterfactual test for explanatory relevance is almost ubiquitously associated with causal explanation. Given that the kind of explanation which is going on when we mention U10-failure in order to explain the bridge-collapse is not one of unification or abstract reasoning, the likelihood that it is causal explanation which is being provided in the above quotations seems all the more likely.

Responsibility: Knowledge of U10-failure was used to assign responsibility for bridge-collapse. This is evident in another passage from the NTSB press release:

The NTSB investigation included the examination of original documents on the bridge design and discovered that the final design plans specified that the U10 gusset plates be $1 / 2$ inch in thickness, rather than at least one inch thickness as required. The Board discovered that the design error was the result of the failure of the bridge design firm, Sverdrup \& Parcel, to perform all the necessary calculations. Furthermore, the investigation revealed that Federal and State procedures for reviewing and approving bridge design plans and calculations were insufficient.

The link between causation and assigning responsibility is well established (see, e.g., Collingwood 1940; Hart and Honoré 1985). If responsibility for the bridge-collapse was to whichever party designed, built and checked-over the U10 gusset plates, this also appears to be strong indication that the event in which the U10 plates deformed, i.e. U10-failure, was a cause of the bridge-collapse.

Control: To determine whether some variable may be controlled via intervention on another we need to assess whether the second variable has the capacity for such control. While it might be misleading to say that the gusset plates had the capacity to bring about bridge-collapse, it is evident that they failed to have the capacity required to prevent the collapse-something they were expected to have. So much is clear from the Holt and Hartman quote above and from a further passage from the National Transport Safety Board press release which concluded that,

the I-35W bridge was flawed from the beginning. [...] Additionally, the cumulative weight from two previous construction modifications, plus the concentrated weight of the construction materials and vehicles, and the traffic weight on the day of the accident exceeded the capacity of the U10 gusset plates.

One feature of causes is that they are often a point of control for their effects (see Cartwright 1989; Woodward 2003; Illari and Russo 2014). Clearly the discussion of the capacity of the gusset plates indicates that their behaviour was such a point of control for the bridge's behaviour. A controlled collapse, for example, could have been brought about earlier if U10-failure was instigated at an earlier time, or else, controlling the duration and manner of U10-failure would have been a way to control the way in which bridge-collapse occurred. Moreover, it seems there is evidence to support the claim that the collapse could have been prevented entirely if the gusset 
plates had been thicker, implying that the gusset plate's dimensions were a point of control for the collapse.

Satisfaction of these three platitudes of causation provides, I think, pre-theoretical reason to believe U10-failure was a cause of bridge-collapse. If the above reasoning regarding parthood and causation is correct, then the collapse of Bridge 9340 is sufficent to establish PWC, since PWC only demands that there exist at least one entity which causes the whole of which it is a part. Of course, it is consistent with this outcome that there be no other cases in which entities cause the wholes of which they are a part, which might not count as much of a victory for PWC. However, there do not appear to be any salient features of the case-study which would lead us to think it is unique in this way. If U10-failure really is a cause of the bridge-failure of which it is a part, then I see no reason not to think there are many other examples of part-whole causation too.

Some careful handling of this example is certainly required. To reiterate the point made in Sect. 1, given how entrenched the distaste for PWC is in philosophy of causation, I don't take the example presented here to be sufficient on its own to establish it. It is, of course, possible to interpret the bridge example as one in which U10-failure causes merely the rest of bridge-collapse, or perhaps to limit focus only to the 'highlevel', non-constitutive causes of bridge-collapse, such as the designers' oversight. ${ }^{7}$ Such interpretations might well reclaim much of the causal intuition which is present when we interpret the situation as one of full-blown part-whole causation-although, of course, they won't reclaim it all.

I don't deny that such alternative interpretations are available, even 'easy'. What I question is the requirement that such interpretations are necessary. Without philosophical prejudice, I think our natural inclinations are to deem U10-failure both a part and cause of bridge-collapse. Moreover, bridge-collapse appears to be a clearly individuated event, arguably more so than the event of all-the-bridge-but-the-U10-gusset-plates collapsing. In choosing to reinterpret the situation as one in which U10-failure causes the latter event but not the former we are sacrificing conceiving the causation in the scenario in terms of clearly individuated and salient relata for the sake of a belief that PWC cannot be correct. Without philosophical argument, such a reinterpretation can seem completely unwarranted. This places the burden of proof firmly on those who would deny PWC to supply such an argument.

To get clearer on the dialectic, we might compare the bridge example, as one anonymous reviewer did, to a case which shares many structural similarities with the bridge-collapse case and yet does not seem so clearly to be a case of part-whole causation. Imagine the first in a line of dominoes spontaneously topples onto the second leading to all the dominoes falling one after the other. Should we say of the situation that the first toppling caused the whole line to fall (i.e. a case of part-whole causation) or only that it caused the line minus the first domino to fall? I do not know what we should say of this case. But I take it that the part-whole causal claim in this scenario is far from nonsensical. And if we do deny the part-whole causation in this case, first, this needn't be based on a wholesale rejection of all possible cases of part-

\footnotetext{
7 I am here indebted to two anonymous referees for pressing me on this issue.
} 
whole causation (we might still accept part-whole causation in the bridge example), and second, if it so based, the rejection requires philosophical argument.

As a final point on the matter. I take it that it might often be the case that certain 'high-level' causes of an event such as bridge-collapse will be understood as causally sufficient (in some sense) for the event. This might bring into doubt the legitimacy of positing a 'low-level' cause such as U10-failure. But I do not think the sufficiency justifies the doubt. In the bridge example, it is arguable that high-level causes, such as the incorrect designing of the gusset plates, were causally sufficient for bridge-collapse because they caused U10-failure. In this way, U10-failure screens off the causal influence of the high-level causal influence on bridge-collapse. ${ }^{8}$ This observation might lead one to wonder whether part-whole causation will exist anywhere in which a phenomenon's underlying mechanism is causally influenced by external high-level phenomena. Such ubiquity would not be an unwelcome result in my opinion; as I said, I think there are many examples of part-whole causation. Accepting a world rife with part-whole causation is only a problem if there are good arguments against it, and as I hope to show in the next section, most of the arguments which have been presented to this end are not good enough.

\section{Philosophical arguments against PWC}

We might be inclined to suspect (as some have in response to earlier presentations of the thesis) that PWC lies in tension with the basic edicts of mereology. Mereology is the study of the relationship between parts and their wholes, and a potential point of disagreement with PWC might draw on the intuition that mereology implies parts and wholes are related in a way that causes and their effects are not.

Is there any support for this intuition? Certainly, the commonly agreed upon axioms of mereology do not stand out as obviously inconsistent with the existence of causal relations between parts and their wholes. However, further consideration of how parts are related to wholes does suggest some further characteristics which are only controversially attributed to causal relations. In what follows of this section I will deal with what I take to be the two central characteristics supposed of part-whole relations which have lead philosophers to object to PWC. The first is that parts are spatiotemporally included in their wholes; the second is that parts and wholes are not 'distinct' in some ontological sense. I discuss these respectively in Sects. 3.1 and 3.2.

\subsection{Spatiotemporal inclusion and PWC}

Parts seem to be included within their wholes both in time and space (or perhaps more correctly, in spacetime). This has lead to a number of philosophers voicing their disagreement with PWC. Here I consider first the intuition that it is the temporal inclusion of part-whole relations which is a problem for PWC and then consider their spatiotemporal inclusion in general.

\footnotetext{
8 This is not trivial, since not all parts of an event screen off its causes.
} 
A widely held opinion is that parts and their wholes are always 'synchronic' or 'atemporal' (e.g. Hüttemann 2004, 2009; Craver 2007; Craver and Bechtel 2007). Perhaps even more widely held, is the opinion that causes and their effects are never synchronic, but are instead sequential (e.g. Hume 1738, 1777; Russell 1912; Mellor 1995; Kim 2000; Craver 2007; Craver and Bechtel 2007). If these intuitions were both correct PWC would be false, since the two conditions on parthood and causation are mutually incompatible. As Craver points out,

$\ldots$ if one is committed to the idea that causes must precede their effects, then constitutive relationships are not causal relationships (Craver 2007, p. 153).

That parts and wholes are always synchronous is not immediately obvious, since presumably part of an event may only occur for a small period of the time in which the whole event is occurring (U10-failure and bridge-collapse are plausibly related in this way). In this case, the claim of synchronicity between parts and wholes should perhaps be understood as one of temporal inclusion, where one event is temporally included within the time of another other if and only if it begins no earlier than and ends no later than that other.

It seems reasonable to grant that when it comes to events, necessarily parts are temporally included within the time of their wholes. ${ }^{9}$ Do we thereby have sufficient grounds to reject PWC? I do not think so. For we have good reason beyond partwhole relations to believe in the existence of causes which exist within the times of their effects. Recall Kant's famous example of the presence of a lead ball causing an indentation in his cushion (Kant 1998, p. A203); or Tooley's example of the movement of one end of a pencil causing the other to move (Tooley 1987, pp. 107-8). Prima facie, these are examples where the cause is temporally included within (possibly even enduring for the entirety of) the time of its effect.

No doubt, these examples will be objected to on account of special relativity. Arguably, it is in fact not true that the presence of the lead ball at $t$ causes a depression in the cushion at $t$, nor that the movement of one end of the pencil at $t^{\prime}$ causes the movement of the other end at $t^{\prime}$. This is because these pairs of objects have distances between them, and the application of force across any nonzero distance $d$ takes time $t \geq d / c$ (where $c$ is the speed of light in a vacuum). But notice that we may accept this point without denying simultaneous causation altogether. After all, the laws of physics do not prohibit simultaneous causation when causes are spatiotemporally included within their causes, as we are assuming is the case with part-whole relations.

Admitting causes which are spatiotemporally included within their effects is bound to offend some sensibilities (see Mellor 1995, Fenton-Glynn 2012 for a discussion). A denier of PWC might further their demands that causal relata not only be necessarily temporally sequential but also non-spatially collocated. ${ }^{10}$ However, this is no better

\footnotetext{
9 Here the operator takes wide scope (it may be possible for some part not to be temporally included within its actual whole in a world where it is not a part of that whole). Even with wide scope, this assumption might itself be questioned. Nonetheless, since accepting the condition of temporal inclusion gives the denier of PWC a stronger position: if my argument for PWC is consistent with that assumption, it will also count for PWC under the assumption's denial.

10 I have ignored in the main text a third option that causes might be spatially collocated with effects as long as they are not temporally coincident. If we believe there to exist some sequential causation, surely
} 
position for the denier of PWC. For instance, although Lewis denied PWC, he was open to simultaneous and spatially coincident causation. He imagines goblins made of matter which passes through ours such that we are not aware of each others' presence. A battle between them taking place in the same spacetime region as his lecture might, he thought, nonetheless stand in causal dependence with it (Lewis 1986d). ${ }^{11}$ Moreover, consideration of the physical laws should in fact prompt us to embrace cases in which causes are spatiotemporally included within their effects. As Huemer and Kovitz point out,

the Lorentz equation [...] provides another example of simultaneous causation: a body with charge $q$ moving at velocity $v$ through electric and magnetic fields experiences a force given by

$$
\vec{F}=q \vec{E}+q \vec{v} \times \vec{B}
$$

where $\vec{E}$ and $\vec{B}$ are electric and magnetic field vectors at the body's current location in space [...] Bodies always experience the effect of the electromagnetic field at their location in space and time. (2003, p. 560)

Not only do we have simultaneity of the charge's acceleration with the application of the electric and magnetic fields, but the charge is also completely spatially collocated with the portion of the field which is affecting the charge. Here, then, appears a clear example of cause and effect being wholly included within each other's spacetime. ${ }^{12}$

In contrast with the criticism raised against the less scientifically-motivated examples, the charge in the field example is not only consistent with relativistic transmission of causal influence but supported by it. For the reality of fields themselves is motivated by the non-instantaneous influence of one charge by another charge's acceleration. Given the conservation of momentum, physicists have posited the existence of fields to mediate momentum as it is transferred from one charge to the other across time and space. The field, therefore, permeates and exists between both charges.

Perhaps one might complain that it is wrong to think the Lorentz force law describes causally related variables. After all, in Cartwright's terms (1979), it appears to be a 'law of association' rather than a 'causal law', and to use Hempel's (1965) terms, it appears to be a 'law of coexistence' rather than a 'law of succession'. It therefore falls

\section{Footnote 10 continued}

we will allow that some event in the past may cause an event much later which occupies the same location, e.g. a seed being sown and a tree growing.

11 According to some theories, dark matter interacts with us in this way (thanks to Luke Fenton-Glynn for pointing this out).

12 A recent paper by Easwaran (2014) argues that acceleration can be defined as the future derivative of the past derivative of distance with respect to time, thereby preserving the temporally sequential nature of causation. His solution is ingenious but requires denying that the position at a time be included in the definition of its velocity at that time (see p. 849). While this move coheres with the apparent lack of third derivatives in current physics models and the assumption of continuous changes in derivatives, I maintain that the solution via mathematical manipulation of the traditional logical rendering of derivatives appears ad hoc. Either way, Easwaran's solution does not imply that causation cannot be instantaneous when between parts and their wholes. 
outside of those classes of law these philosophers have argued have a monopoly on covering causal information. One might also object that causation is a macroscopic phenomenon and so not the sort of thing one should expect any law of physics to capture. One could think this as a result of the observation that laws like the Lorenz force law are time symmetric. Just as the kinematics of gases at the microlevel does not alone give rise to the time asymmetry explicit in laws like the second law of thermodynamics, similarly we might infer that time symmetric microlevel laws in general will not alone give rise to the time asymmetry of causal relations (see, e.g., Papineau 2013).

I have no complaint with the general point that coexistential, time symmetric laws of association like the Lorenz force law are insufficient to ground causal asymmetry. But this is no objection to the apparently natural conviction among physicists that force is an effect of magnetic and electric fields, as is clear from a typical text book which claims of the Lorenz force law that 'once the electric and magnetic fields are known at some point in space, the force those fields exert on a particle of charge $q$ can be calculated from the expression' (Serway and Jewett 2006, p. 809, my emphasis). Notice that the numerical equation itself need not entail the causal asymmetries between the variables for them to exist. And I think we have strong grounds to trust the intuition that they do exist. After all, we can manipulate force via an intervention on charge, magnetic field and electric field, whereas a manipulation of any of the latter via intervention on the former is not typically possible. If we think that the possibility of manipulation via intervention is an indication of a causal relationship, then we should agree with Huemer and Kovitz. Moreover, and perhaps as a consequence of our knowledge of the possibility of manipulation via intervention, the fields and charge seem to explain, are points of control and can be used to assign responsibility for the value of force experienced by an object. Finally, these conclusions need not interfere with the conviction that causation is macroscopic. For it may well be that facts about what variables can be manipulated via intervention in the Lorenz force law are partly explained by further perspectival facts or facts about the multiple realisability of thermodynamic macroscopic states which go beyond the information in the physical laws ( cf. Woodward 2003, esp. §5.3).

We clearly have good reason to accept the existence of causal relationships between the electrical and magnetic fields a charge is in and the force it experiences as a consequence. Crucially, these causal relationships differ from that of U10-failure and bridge-collapse in which the spatiotemporal inclusion of the former in the latter is assured by virtue of the former being part of the latter. While the force on a charge and the presence of the field do not obviously have this part-whole relation they nonetheless also admit of spatiotemporal inclusion. If we accept the example, therefore, it cannot be spatiotemporal inclusion which motivates a denial of the bridge-example being an instance of PWC. ${ }^{13}$

Of course, the acceptance of simultaneous causally related events means that we cannot simply reduce the direction of causation to the direction of time (or vice versa). It's not clear that this would have been a straightforward project anyway, since causal

\footnotetext{
13 The example also serves to undermine the plausibility of Kim's (2000) 'Causal-Power Actuality Principle' which demands expressions of causal powers to come after the power's determining property has been acquired.
} 
influence has not generally been thought to be transmitted at a constant rate. But nor is it clear that the connection between the asymmetries of time and causation needs to be wholly severed, since simultaneous causation does not imply that retro-causation is possible. As long as the causal influence of events spatiotemporally included in effects does not act backwards in time, then there remains a temporal asymmetry in causation in general despite the possibility simultaneous causal occurrences. Consequently, the direction of causal overdetermination (if there is one) and the screening of effects of common causes can inherit such an asymmetry as well. The desire to retain these features of causation is, therefore, not thwarted by an acceptance of PWC.

\subsection{Ontological distinctness and PWC}

Perhaps the dominant reason for rejection of PWC alongside concern about spatiotemporal inclusion is the conviction that causes and their effects are distinct from each other in a way that parts and their wholes fail to be. As Lewis once remarked,

when one event is part of another, whether essentially or accidentally, they are not identical but they are not distinct either [...] [E]vents which are not distinct cannot stand in causal dependence. (Lewis 1986d, p. 259)

In this context, the notion of indistinctness between two entities gestures at a number of more specific relations which incorporate some element of metaphysical necessity, typically cashed out as a kind of ontological independence. I consider a relation of ontological distinctness to cover any of these more nuanced relations. Hence, Lewis remarks that any two causal events,

$C$ and $E$ must be distinct events - and distinct not only in the sense of nonidentity but also in the sense of nonoverlap and nonimplication. It won't do to say that my speaking this sentence causes my speaking this sentence or that my speaking the whole of it causes my speaking the first half of it; or that my speaking causes my speaking it loudly, or vice versa (Lewis 2000, p. 78).

Here Lewis mentions three criteria of ontological distinctness: nonidentity, nonimplication and nonoverlap. Scrutiny of Lewis's definitions reveals these to be ontological forms of distinctness in the sense that they make appeal, in part, to various strong forms of ontological dependence. I will address the question of whether nonidentity and nonimplication threaten PWC in turn in Sects. 3.2.1 and 3.2.2. Nonoverlap concerns the distinctness of entities which fail to share a part (Lewis 1986b, p. 259) and so is presumably only relevant to rejection of PWC in its prohibition of those special cases where shared parts are identical with one of the entities involved. We will thereby cover all relevant discussion of nonoverlap when we consider nonimplication. I will argue that consideration of these relations does not reveal any reason to reject PWC. However, as we have seen, Lewis did certainly think that parthood was incompatible with causation and in Sect. 3.2.3 I will address whether or not Lewis's criterion that causes and effects should be distinct in his specific sense of 'nonparthood' is a plausible argument against PWC. 


\subsubsection{Nonidentity}

Nonidentity holds between everything and anything which is not itself (i.e. the complement of identity). Should nonidentity be a criterion for causal relations? Many people have thought so. It is a natural assumption that events are not 'causa sui', i.e. they must not be their own causes, and this is just another way to say that identity is a relation which prohibits causation between its relata.

Let us grant this assumption. ${ }^{14}$ In the case of bridge-collapse we are not considering whether some event identical with it was its cause, as we might be if considering whether the entire sum of parts were its cause (see Fazekas and Kertész 2011). Instead, we are considering specifically whether U10-failure was its cause. And it is certainly not the case that U10-failure is to be identified with bridge-collapse, for they occur for different periods of time and in different places (although the time and location of the former is included in that of the latter). So much is clear from the fact that the U10 plates were only two of multiple components in the bridge (such as the L10 trusses and U11 gusset plates) many of which continued to buckle after the U10 plates had failed). So PWC cannot be rejected on the basis that parts are to be identified with their wholes, since some parts are not identical with their wholes; they are proper parts. The relationship between U10-failure and bridge-collapse is a case in point.

At this point one might consider two further principles concerning identity and parthood (as one anonymous reviewer did) both of which might be used to generate concern even in the case of causation between wholes and their proper parts. The first principle that composition is identity (or, perhaps, merely a kind of identity, see Noonan and Curtis 2017, §8) asserts that entities are identical to what they are composed of. Though controversial, it has been defended in various forms by a number of philosophers (e.g. Baxter 1988, 2001; Lewis 1991; Sider 2007; Cotnoir 2013). Of course, this does not entail that every part is identical to the whole, but it might be taken to imply that parts are partially identical with their wholes. If that's the case, one might worry that accepting PWC would allow for wholes to be 'partially causa sui'.

But the problem for someone who wants to make use of this to ground an objection to the thesis of PWC is that it is entirely unclear how to get from an agreement both that events should not be causa sui and that parts are partially identical, to any kind of actual inconsistency with the thesis. To do so, we need to know in what way the indistinctness brought about by partial identity is similar to that brought about from identity simpliciter, and further, whether that similarity is sufficient to block PWC on the basis that entities cannot cause themselves. In short, we need to know why we should believe that being partially causa sui is problematic in the same way as being causa sui is. As far as I am aware, no such argument has been provided.

A different issue comes from acceptance of a second principle that all causes of any event are causes of all the events which are parts of those events. Unlike the

\footnotetext{
14 There are known solutions to Einstein's field equations which admit closed timelike curves which may ultimately force us to relax our belief that nothing could possibly be causa sui. Nonetheless, the self-causing systems made available with closed timelike curves will still be mediated by temporal-like distance-i.e. where the cause exists in its own future lightcone.
} 
previously considered principle of composition as identity, in combination with a rejection of events which are causa sui, this principle does seem to be in contradiction with PWC. This is because a part which is a cause of its whole would, according to the principle, be a cause of itself. But also unlike the former principle, the idea that causation distributes over the parts is not much defended in philosophical literature, and it is easy to see why.

Most philosophical analyses of causation do not try to say why one and only one event is the cause of another, but rather seek to find those events which each count as a cause of that other event. As Lewis (1973) remarked, the former project can appear one which makes unreasonable (or even 'invidious') discrimination. But to be a cause of an effect, it needn't be the case that the cause explain or be causally responsible for every aspect of the effect, let alone every one of its parts. After all, there may be aspects or parts to which we can attribute other causes or even no cause at all. Such observations are enough, I think, to make us doubt that causes of an event always distribute over the event's parts.

As things currently stand, there do not appear to be sufficient arguments to conclude from the requirement that causes be distinct from their effects in the sense of nonidentity that PWC is false.

\subsubsection{Nonimplication}

There is a tradition in philosophy dating back as far as Hume that the distinctness of entities should be understood in the sense of a kind of nonimplication.

There is no object, which implies the existence of any other if we consider these objects in themselves, and never look beyond the ideas which we form of them. (Hume 1738, Bk I, III, IV.)

Although Hume's own views about concept-acquisition and meaning did not permit him to clearly disambiguate between metaphysical and logical implication, for our purposes we want to consider the plausibility of Hume's sentiment interpreted as a denial of metaphysical implication: in which one entity implies the existence of another if and only if it (or its counterpart in another possible world) cannot exist without, i.e. is not ontologically independent from, the existence of that other (or its counterpart). Notice that were such a distinctness of nonimplication to hold between a cause and its effect, it would have to hold in both directions: the cause would not be ontologically dependent on its effect nor would the effect be ontologically dependent on the cause.

Nonimplication in this purely ontological sense (we will consider Lewis's more complex notion in Sect. 3.2.3) may indeed be the criterion of causation Craver and Bechtel had in mind when denying PWC; their idea being that while causes and effects do not entail each other's existence (they can exist independently of each other) parts and their wholes do exhibit such entailments. Witness, for example, Craver's own invocation of this line of argument:

"[I]n the constitutive relation, a token instance of the property $A$ is, in part, constituted by an instance of the property $B$; as such, the tokening of $B$ is 
not logically independent of the tokening of A. At least since Hume, many philosophers have held that causes and effects must be logically independent." (2007, p. 153)

Although Craver here uses the word 'logical', we may infer the relevant independency relationships he references to be ontological. After all, no constitutive relationship considered in Craver (2007), Craver and Bechtel (2007) is such that there is a purely logical entailment between part and whole. The sense of 'logical independence' here seems to be more like the notion of nonimplication just defined, i.e. one of existential or ontological independence. ${ }^{15}$

Despite the heritage in Hume's own work, the so-called 'Humean' reasons for rejecting such dependency relations between cause and effect have changed since Hume first wrote on the matter. Hume's own disagreement stemmed from a belief that 'one event follows another; but we can never observe any tie between them' (Hume 1777, Sec. VII, part II). But focus on the issue of observation of connections between cause and effect has subsided in the recent Humean tradition. This is partly because of the persuasiveness of experiments such as those first performed by Michotte (1963), but furthermore because the existence of an observable connection is now generally admitted (pace radically empirical grievances) to be independent of the existence of a necessary connection of ontological dependence.

Instead, contemporary denials of metaphysically necessary connections between cause and effect are often promoted-when they are promoted at all-on semantic grounds. On the most popular account of the semantics of counterfactuals, we consider worlds similar to ours with respect to its laws of nature and matters of fact but for the minimal violation of those similarities in order to establish the counterfactual's antecedent. Following Lewis (1986c), this violation is described as a 'miracle' since it will likely contradict some actual law of nature in order to bring about a different history from the time just before the counterfactual's antecedent towards the future while keeping the past as it actually is. Since violation of a natural law entails the law's lack of metaphysical necessity, the employment of the notion of a miracle demands that effects don't follow of metaphysical necessity from their causes. Otherwise, we could not entertain counterfactual scenarios in which the effect has not occurred but the cause has.

If actual causes could all have occurred without being followed by their respective effects then they are indeed ontologically independent of (in the sense that they do not metaphysically imply) those effects. But it is certainly not the case that parts always fail to be ontologically independent of their wholes. Even if we accept that U10-failure is part of bridge-collapse, we might plausibly also hold that the event U10-failure could have occurred without the event bridge-collapse, so long as some supporting mechanism were in place under the bridge, or perhaps U10-failure could have been brought about in a strong enough vice without the bridge ever having been

15 Craver and Bechtel are specifically concerned with constitutive relationships between mechanisms and their component parts. However, it is reasonable to assume that these relations are a subset of those related as part to whole, and moreover, that their arguments are intended to carry over to the more general relation. 
built. The same goes for other examples. ${ }^{16}$ So if the required ontological independency mentioned by Craver is that of the cause on the effect, PWC cannot be objected to on the grounds that part-whole relationships cannot accommodate this independency.

It is important to note that the only dependence that must be denied for semantic reasons (assuming the semantics is correct) is that of causes on their effects. So, if this is the only reason why Humeans deny certain ontological dependencies between causal relata then it cannot serve to prohibit dependencies of effects on their causes. Still, Hume's claim was that no object implies the existence of any other, suggesting for him, at least, that the ontological independency of causes and effects goes both ways. While the above semantic considerations do not demand the ontological independency of effects on their causes, considerations of certain causal scenarios (such as preemption) may seem to. The pertinent question, then, is how much ontological independency is required of effects from their causes, and are part-whole relationships necessarily incompatible with that? I offer two points.

First, while some effects do seem ontologically independent of their causes, this may not be a general fact about causation. And we do not have to become embroiled in the controversial metaphysics of dispositional essentialism (e.g. Swoyer 1982; Ellis 2002; Bird 2007) to see why. Consider, for example, the connection between a particular mutation in the genome of a hominid a very long time ago and the subsequent existence of the human species. It seems plausible that the latter was caused by the former and moreover, that the latter event ontologically depends on the former. There is no world in which the human species exists but there was no mutation in the primate order. If one has any inclination to agree with the essential nature of some organisms' origin, then one will likely accept that causal relationships such as this also exhibit an ontological dependency of the effect on the cause. Hence, even if wholes do sometimes depend on their parts ontologically, this is not a fact which should prohibit us from entertaining the idea that a causal relationship might exist between them as well.

Of course, one might simply reject that any event has an essential origin. Such a view is not without its supporters. Still, it is notable that the commonplace rejection of PWC on the grounds that effects should not be ontologically dependent on their causes requires such a rejection. A different option is to define nonimplication in such a way that it is compatible with cases of the essential origins of certain effects. Although it is unlikely Lewis had such a motivation, a close reading of Lewis might lead us to attribute to him his own definition of nonimplication which is compatible in this way. For Lewis,

... an event $e$ implies event $f$ iff, necessarily, if $e$ occurs in a region then also $f$ occurs in that region (Lewis 1986d, p. 255).

In these terms, implication is a conjunction of spatiotemporal inclusion (due to the requirement of occurrence within the same region) and of ontological indistinctness

\footnotetext{
16 The change in confirmation of rhodopsin is a part of the phenomenon of rod cell activation in the eye's retina. But the confirmation is not dependent on the activation as a whole and might occur independently if, say, the G-proteins the rhodopsin is supposed to stimulate is absent from the cell.
} 
(due to the requirement of necessary occurrence). ${ }^{17}$ Consequently, we may consider that for Lewis, the complement of implication, viz. 'nonimplication', would have been been a disjunctive relation: causes and effects are related by nonimplication if and only if either they are not related by spatiotemporal inclusion or they are not related by ontological dependence. Under such a definition, one could assert that causes and effects must be distinct in the sense of nonimplication while acknowledging cases of essential origin. For arguably, the origin of some species (e.g. in the mutation of some genome in that species' ancestors) is not spatiotemporally included in the event of the continuing existence of that species.

On reflection, it might seem rather odd to require that cause-effect pairs satisfy such a disjunctive relation. Indeed, I think it is unlikely that it is this interpretation of nonimplication Lewis had in mind when he suggested that causes and effects should be distinct in its sense. Lewis was famously a Humean. Consequently, he worked under the dictum that causes and effects do not have necessary connections between them (e.g. Hume 1738, 1777; Lewis 1986e). ${ }^{18}$ While the definition of nonimplication in purely metaphysical terms seems to match this dictum, the disjunctive sense drawn from the complement of Lewis's definition of implication appears unreasonably weak to match his Humean sympathies. We know, at least, that Lewis did believe causes and effects to be distinct in the purely metaphysical sense of nonimplication (and so would have denied essential origins). When we notice also that the relevant passages from Lewis are from entirely different works separated by more than a decade it becomes reasonable to think that Lewis had the purely ontological sense of nonimplication in mind when listing the required characteristics of causation. ${ }^{19}$

Whether or not such an disjunctive interpretation of distinctness in the sense of nonimplication really was what Lewis had in mind or not, a second point concerning the suitability of nonimplication in grounding a rejection of PWC is that wholes need not in general be ontologically dependent on their parts: they may be multiply realisable. We might accept, for example, that the collapse of the Bridge 9340 did have as a part the deformation of the U10 gusset plates but deny that it had that part necessarily. As we have heard, the bridge was 'fracture critical', meaning that it was liable to collapse under a high proportion of possible failures among its parts. This might suggest that the very same event bridge-collapse could have occurred in scenarios in which U10-failure did not. As long as we individuate bridge-collapse reasonably coarsely, the fracture-critical nature of the bridge is enough to secure the ontological independence of bridge-collapse from U10-failure.

What an assertion of multiple realisability of wholes of this sort amounts to is a denial of the principle of Mereological Essentialism: that wholes have their parts essentially. The principle is, in general, highly contentious. Enduring objects are typ-

\footnotetext{
17 More precisely, the ontological aspect takes wide scope such that the the implied event necessarily occurs in the same region as $e$ whenever $e$ occurs.

18 Contrast Humeans, e.g., with causal necessitarians (e.g. Shoemaker 1997; Bird 2007; Wilson 2010) and by sympathisers with the essentiality of origin.

19 Lewis's definition of implication, from which I drew the complementary definition of nonimplication appears in his essay Events, (Lewis 1986d), whereas his stipulation that causes and effects be 'distinct in the sense of nonimplication' appears in his essay Causation as influence, (Lewis 2000).
} 
ically understood to change their constituent parts over time, and even when they do not, we assume they are able to, or at least could have been constituted differently. The intuitions may not be as strong in the case of events, since it is often argued that events are 'occurrents' rather than 'continuants', taking up time by persisting through it by virtue of the existence of their temporal parts (see Mellor 1980; Simons 2000; Casati and Varzi 2015). In this sense, events can't change across time in the way many think that objects can (although this in itself is controversial). But this restriction is alone insufficient to justify the belief that events cannot vary in constitution across modal space.

Indeed, none of the three most popular ontologies of events preclude the sort of multiple realisability of events being suggested in the bridge-example (see Kim 1976; Davidson 1976; Lewis 1986d). Of course, this openness relies on our not understanding events related as part to whole to be so 'modally fragile' (to use Lewis's 1973, 2000 terminology) that they couldn't exist independently of each other. But the implausibility of this understanding is argued for by Lewis himself, who admits that,

... we have no business first saying as usual that the very same event might have been significantly delayed and changed, and then turning around and saying that it is caused by an event without which it would have been ever so slightly delayed and changed, and then saying that this is because it takes only a very slight delay or change to turn it into a different event altogether (2000, p. 86).

It seems all the more plausible, therefore, that bridge-collapse could have occurred without U10-failure, even though the latter was actually part of the former. Hence, there are parthood relations which exhibit ontological independence of the part from the whole and the whole from the part. Consequently, we cannot ground a rejection of PWC in a criterion of nonimplication understood either purely in terms of ontological dependency or in the disjunctive terms drawn from the complement of Lewis's definition of implication between events.

\subsubsection{Nonparthood}

Lewis's remark that causes and effects should be distinct in the sense of nonidentity and nonimplication appears to remain insufficient to ground a rejection of PWC. The criterion of nonidentity is not incompatible with proper parts causing their wholes and nonimplication understood either purely in terms of ontological dependence or in disjunctive terms as a prohibition of either ontological dependence or spatiotemporal inclusion does not appear to exclude all part-whole relations (e.g. when the wholes are multiply realisable).

But perhaps it is wrong to put all of Lewis's argumentative weight against PWC on these relations. For Lewis also provided a definition of parthood itself which goes beyond any straightfoward combination of these relations. 'Let us say', he writes, that,

occurrent event $e$ is part of occurrent event $f$ iff some occurrent event that implies $e$ is essentially part of some occurrent event that implies $f$. (1986d, p. 259) 
Essential parthood is then interpreted as a form of implication (in Lewis's sense), in which the implied event necessarily occurs within the spatiotemporal boundaries of the implying event, i.e.,

$e$ is essentially part of event $f$, iff, necessarily, if $f$ occurs in a region, then also $e$ occurs in a subregion included in that region. (p. 258)

Like Lewis's definition of implication, his definition of parthood requires that parts be spatiotemporally included within (i.e. be a subregion of) their wholes, inheriting one of the criteria of part-whole relationships assumed in Sect. 3.1. But crucially, the metaphysical component of Lewis's parthood relation is considerably weaker than those considered in Sect. 3.2.2, since it "covers not only the case in which $e$ is essentially part of $f$, but also the case in which $e$ is only accidentally part of $f$, and $f$ could have occurred without having $e$ as a part' (p. 259). Even so, Lewis clearly thought some element of ontological dependency should play a role in defining parthood. For even when wholes do not have their parts essentially, Lewis's definition requires there to be two more modally 'detailed' events related as part to whole where the whole $i$ s ontologically dependent on the part and where both detailed part and whole respectively depend ontologically on the less detailed part and whole.

We might well wonder whether Lewis's characterisation of parthood really does accurately capture all and only parthood relations. For instance, it is entirely unclear whether U10-failure satisfies Lewis's condition of being a part of bridge-collapse. In order for one to be part of the other Lewis's definition requires there to exist an event which implies bridge-collapse and has an essential part which implies U10-failure. We could try to come up with some gerrymandered event which might satisfy this criterion, such as the U10-failure-originated-bridge-collapse. But this may seem to commit us to a rather spurious entity. Assuming U10-failure and bridge-collapse are indeed related as part to whole, the alternative is to admit that Lewis's definition of parthood is incorrect.

Nonetheless, let's assume for the moment that Lewis got the definition right. His characterisation of parthood allows us to consider the relation achieved by its negation: nonparthood. Two events $a$ and $b$ satisfy the relation of nonparthood if and only if they do not satisfy the parthood relation; i.e. there is no third event $c$ which implies either $a(b)$ and is essentially part of a fourth event which implies $b(a)$. From the opening quote of Sect. 3.2, it is plausible that Lewis would have believed nonparthood to be a requirement of causal relations. And since Lewis's characterisation of parthood is weaker (i.e. more inclusive) than his notion of implication, its negation, nonparthood, will be stronger (i.e. more exclusive) than the corresponding relation of nonimplication (in either sense discussed above). So, where nonimplication failed as a suitable criterion of distinctness for rejection of PWC due to a failure to exclude all part-whole relations (when, e.g., wholes are multiply realisable), the relation of nonparthood may have more success.

But of course, in this context it would be question-begging to say that parts cannot ever cause their wholes because parts and wholes are not appropriately distinct in the sense of nonparthood. What must be provided is a reason to think that distinctness in the sense of nonparthood is requisite for causes and their effects. Moreover, its far from clear that Lewis can call upon the same Humean intuitions to justify nonparthood 
as a criterion of distinctness for cause-effect pairs as with nonimplication. As we saw, the problem with nonimplication (in either the purely metaphysical sense or in the disjunctive terms of the complement of Lewis's definition of implication) was that it was satisfied by parts and wholes which are multiply realisable and so as a requirement on causal relaitons it fails to ground a rejection of PWC. Because of its strength, the requirement that causes and effects be distinct in the sense of nonparthood may not suffer this problem, but endorsing it as a requirement comes at the cost of no longer being motivated by a prohibition of necessary connections. It therefore fails to be justified as a condition on cause-effect pairs, even from the partisan perspective of the Humean.

So, what could be the motivation for this more restrictive criterion on causal relationships? Lewis provides no argument. He does, however, draw on a motivational example of Kim's (1973) in the text omitted from the above quote included below.

When one event is part of another, whether essentially or accidentally, they are not identical but they are not distinct either [...] Kim gives the case of someone who writes "Larry," and as part of that event writes "rr." [...] [E]vents which are not distinct cannot stand in causal dependence. (My emphasis.)

It seems for Lewis, Kim's toy example example does sufficient work of helping us see why causes and effects could not be related as parts to wholes. But I do not think it is at all clear why. First, while the writing of 'Larry' will certainly have as a part the writing of 'rr', and in this sense the events fail to be distinct in the sense of nonparthood, there appear contexts in which it might seem natural to posit a causal connection between the two as well. Perhaps the writer is compelled by forces deep in her psyche to afterwards prefix any 'rr' she writes with the letters 'La' and suffix them with ' $y$ '. Perhaps she wished to write 'embarrassed', but as soon as the two 'r's were written, she couldn't help but amend the phrase to read 'Larry'. Under such circumstances, it could very well seem appropriate to say that the writing of ' $r r$ ' caused her to write 'Larry'. To repeat a point made about the bridge-example, I do not deny that there are coherent interpretations of the scenario in which the writing of ' $r$ ' ' is only understood as causing the writing of 'La...y', or in which we focus only on the high-level causation between her psyche and what she writes. The point is only that without philosophical argument the interpretation of part-whole causation seems natural (or at least not unreasonable) and the need for reinterpretation undermotivated. Exactly what I have been assessing over the past few sections is whether the philosophical arguments for such a reinterpretation are justified.

Second, and perhaps more significantly, regardless of whether the elaborated 'Larry'-example is considered plausible or not, we can grant that no causation exists between writing 'rr' and writing 'Larry' and still deny that it is the criterion of nonparthood which is prohibiting it. Other than the fact that finite examples of a correlation between part-whole relationships and a lack of causation do not constitute a proof that causal relationships are incompatible with part-whole relationships, it is not even clear that this particular example is of the right sort to even suggest such an incompatibility. For the example of someone writing 'Larry' is arguably one of essential parthood, i.e. there is a relation of ontological dependence between them: the writing 
of 'Larry' could not have been written without the writing of 'rr'. Pursuing a Humean line, perhaps in this case 'it won't do' to call the parts a cause of its whole. But then the reason we deny causation in this case is not because the relations are not distinct in the sense of nonparthood, but because they are not distinct in the sense of nonimplication. If Lewis and those who draw on his characterisation of parthood want to persuade us that no whole - not even the multiply-realisable ones-can be caused by any of its parts then we need to be provided with an argument, or at least some more appropriate motivating examples. The 'Larry'-writing example does not do this.

\section{Conclusion}

There may exist arguments which do show that parts cannot ever cause their wholes, but those provided above are not among them. There is a lingering intuition in philosophical literature that the relata of parthood relations cannot also be related causally. This comes both from the intuition that causes cannot be spatiotemporally included within their effects and also from the intuition that causes and effects must be ontologically distinct. An exploration of cases captured in physical laws such as the Lorenz force law shows us that causes can be spatiotemporally included within their effects. And unpacking the various ways in which ontological distinctness might have been interpreted by the detractors of PWC shows little individual motivation for rejection of part-whole causation. This is especially the case once we grant that wholes need not have their parts essentially. Pending better arguments, and given the plausibility of the case-study of the collapse of Bridge 9340 in Sect. 2 as an instance of part-whole causation, it appears we should be overall in favour of PWC.

Open Access This article is distributed under the terms of the Creative Commons Attribution 4.0 International License (http://creativecommons.org/licenses/by/4.0/), which permits unrestricted use, distribution, and reproduction in any medium, provided you give appropriate credit to the original author(s) and the source, provide a link to the Creative Commons license, and indicate if changes were made.

\section{References}

Ballarini, R., \& Okazaki, T. (2010). The infamous gusset plates. In P. Nunnally (Ed.), The city, the river, the bridge. Minneapolis: Minnesota Press.

Baumgartner, M. (2013). Rendering interventionism and non-reductive physicalism compatible. Dialectica, 67(1), 1-27.

Baxter, D. L. M. (1988). Identity in the loose and popular sense. Mind, 97, 576-582.

Baxter, D. L. M. (2001). Identity as partial identity. The Australasian Journal of Philosophy, 79(4), 449-464.

Bird, A. (2007). Nature's metaphysics: Laws and properties. Oxford: Oxford Clarendon Press.

Cartwright, N. (1979). Causal laws and effective strategies. Noûs, 13, 419-437.

Cartwright, N. (1989). Nature's capacities and their measurement. Oxford: Oxford University Press.

Casati, R., \& Varzi, A. (2015). Events. In E. N. Zalta (Ed.), The Stanford encyclopedia of philosophy (winter 2015 ed.). Stanfor: Metaphysics Research Lab, Stanford University.

Collingwood, R. (1940). An essay on metaphysics. Oxford: Oxford University Press.

Cotnoir, A. J. (2013). Composition as general identity. Oxford Studies in Metaphysics, 8, 294-322.

Cowling, S. (2014). No simples, no gunk, no nothing. Pacific Philosophical Quarterly, 95, 246-60.

Craver, C. (2007). Explaining the brain: mechanisms and the mosaic unity of neuroscience. Oxford: Oxford Clarendon Press. 
Craver, C., \& Bechtel, W. (2007). Top-down causation without top-down causes. Biology and Philosophy, $22,547-563$.

Davidson, D. (1976). The individuation of events, chapter 22. In M. Brand \& D. Walton (Eds.), Action theory. Dordrecht: Reidel.

Davidson, D. (1985). Reply to Quine on events. In E. Lepore \& B. McLaughlin (Eds.), Actions and events: Perspectives on the philosophy of donald davidson. Oxford: Blackwell.

Easwaran, K. (2014). Why physics uses second derivatives. British Journal of Philosophy of Science, 65 , 845-862.

Ellis, B. (2002). The philosophy of nature: A guide to the new essentialism. Chesham: Acumen.

Fazekas, P., \& Kertész, G. (2011). Causation at different levels: Traking the commitments of mechanistic explanations. Biology and Philosophy, 26, 365-383.

Fenton-Glynn, L. (2012). Getting causes from powers, by Stephen Mumford and Rani Lill Anjum. Mind, 121(484), 1099-1106.

Harinen, T. (2014). Mutual manipulability and causal inbetweenness. Synthese. Online ISSN 1573-0964.

Hart, H., \& Honoré, T. (1985). Causation in the law (2nd ed.). Oxford: Oxford University Press.

Hempel, C. (1965). Aspects of scientific explanation. New York: Free Press.

Holt, R., \& Hartmann, J. (2008). Adequacy of the U10 gusset plate design for the Minnesota Bridge No. 9340 (I-35W over the Mississippi River). Final Report, Technical report, Turner-Fairbank Highway Research Center Report.

Holth, N. (2011). I-35W bridge collapse: Some explanations and thoughts. http://bridgehunter.com/mn/ hennepin/mississippi-35w/

Huemer, M., \& Kovitz, B. (2003). Causation as simultaneous and continuous. The Philosophical Quaterly, 53(213), 556-565.

Hume, D. (1738) [1978]. A treatise of human nature. Oxford: Oxford Clarendon Press.

Hume, D. (1777) [1993]. An enquiry concerning human understanding (2nd ed.). Indianapolis: Hackett Publishing.

Hüttemann, A. (2004). What's wrong with microphysicalism?. London: Routledge.

Hüttemann, A. (2009). Dispositions in physics. In G. von Damschen, R. Schnepf, \& K. Stüber (Eds.), Debating dispositions Issues metaphysics, epistemology, and philosophy of mind (pp. 223-237). Berlin: De Gruyter.

Illari, P., \& Russo, F. (2014). Causality: Philosophical theory meets scientific practice. Oxford: Oxford University Press

Kaiser, M. I., \& Krickel, B. (2017). The metaphysics of constitutive mechanistic phenomena. The British Journal for the Philosophy of Science, 68(3), 745-779. https://doi.org/10.1093/bjps/axv058.

Kant, I. (1998). Critique of pure reason. New York: Cambridge University Press.

Kim, J. (1973). Causes and counterfactuals. Journal of Philosophy, 70(17), 570-572.

Kim, J. (1976). Events as property exemplifications, chapter 23. In M. Brand \& D. Walton (Eds.), Action theory. Dordrecht: Reidel.

Kim, J. (2000). Making sense of downward causation. In P. Anderson, C. Emmeche, N. Finnermann, \& P. Christiansen (Eds.), Downward causation (pp. 305-321). Aarhus: Aarhus University Press.

Lemmon, E. J. (1967). Comments. In N. Rescher (Ed.), The logic of decision and action (pp. 96-103). Pittsburgh: Pittsburgh University Press.

Lewis, D. (1973). Causation. Journal of Philosophy, 20, 11-13.

Lewis, D. (1986a). Causation and explanation. Philosophical Papers II. Oxford: Oxford University Press. chapter 22.

Lewis, D. (1986b). Causation: Postscripts. Philosophical Papers II. Oxford: Oxford University Press. chapter 21.

Lewis, D. (1986c). Counterfactual dependence and time's arrow. Philosophical Papers II. Oxford: Oxford University Press. chapter 17.

Lewis, D. (1986d). Events. Philosophical Papers II. Oxford: Oxford University Press. chapter 23.

Lewis, D. (1986e). Philosophical Papers II. Oxford: Oxford University Press.

Lewis, D. (1991). Parts of classes. Oxford: Basil Blackwell.

Lewis, D. (2000). Causation as influence, chapter 3. In J. Collins, N. Hall, \& L. Paul (Eds.), Causation and counterfactuals (Vol. 97, pp. 182-197). Cambridge: MIT Press.

Mellor, D. H. (1980). Things and causes in spacetime. British Journal of Philosophy of Science, 31, $282-288$.

Mellor, D. H. (1995). The facts of causation. London: Routledge.

Michotte, A. (1963). The perception of causality. London: Methuen. 
Noonan, H., \& Curtis, B. (2017). Identity. In E. N. Zalta (Ed.), The Stanford Encyclopedia of Philosophy (spring 2017 ed.). Stanford: Metaphysics Research Lab, Stanford University.

Papineau, D. (2013). Causation is macroscopic but not irreducible, chapter 5. In S. Gibb \& R. Ingthorsson (Eds.), Mental causation and ontology. Oxford: Oxford University Press.

Quine, W. V. O. (1985). Events and reification. In E. Lepore \& B. McLaughlin (Eds.), Actions and events: Perspectives on the philosophy of Donald Davidson (pp. 162-171). Oxford: Blackwell.

Russell, B. (1912). On the notion of a cause. Proceedings of the Aristotelian Society, 13, 1-26.

Salmon, W. (1998). Causation and explanation. Oxford: Oxford University Press.

Serway, R., \& Jewett, J. (2006). Principles of physics: A calculus-based text (4th ed.). Belmont: Thomson Brooks/Cole.

Shoemaker, S. (1997). Causality and properties, chapter 15. In D. H. Mellor \& A. Oliver (Eds.), Properties. Oxford: Oxford University Press.

Sider, T. (2007). Parthood. The Philosophical Review, 116, 51-91.

Simons, P. M. (2000). Continuants and occurrents. In Proceedings of the Aristotelian Society (Supplementary Volume 74, pp. 59-75).

Swoyer, C. (1982). The nature of natural laws. Australian Journal of Philosophy, 60(3), 203-223.

Tooley, M. (1987). Causation. Oxford: Oxford Clarendon Press.

Wilson, J. (2010). What is hume's dictum, and why believe it? Phenomenological Research, 80, 595-637. Woodward, J. (2003). Making things happen. Oxford: Oxford University Press.

Woodward, J. (2014). Interventionism and causal exclusion. Philosophy and Phenomenological Research, $91,303-347$. 